\title{
Bisphosphonate's and Intermittent Parathyroid Hormone's Effect on Human Spinal Fusion: A Systematic Review of the Literature
}

\author{
Michael A. Stone ${ }^{1}$, Andre M. Jakoi ${ }^{1}$, Justin A. Iorio ${ }^{2}$, Martin H. Pham ${ }^{3}$, Neil N. Patel ${ }^{1}$, \\ Patrick C. Hsieh ${ }^{3}$, John C. Liu ${ }^{3}$, Frank L. Acosta ${ }^{3}$, Raymond Hah ${ }^{1}$, Jeffrey C. Wang ${ }^{1}$ \\ ${ }^{1}$ Department of Orthopaedic Surgery, Keck School of Medicine of USC, Los Angeles, CA, USA \\ ${ }^{2}$ Department of Orthopaedic Surgery, Hospital for Special Surgery, New York, NY, USA \\ ${ }^{3}$ Department of Neurological Surgery, Keck School of Medicine of USC, Los Angeles, CA, USA
}

\begin{abstract}
There has been a conscious effort to address osteoporosis in the aging population. As bisphosphonate and intermittent parathyroid hormone (PTH) therapy become more widely prescribed to treat osteoporosis, it is important to understand their effects on other physiologic processes, particularly the impact on spinal fusion. Despite early animal model studies and more recent clinical studies, the impact of these medications on spinal fusion is not fully understood. Previous animal studies suggest that bisphosphonate therapy resulted in inhibition of fusion mass with impeded maturity and an unknown effect on biomechanical strength. Prior animal studies demonstrate an improved fusion rate and fusion mass microstructure with the use of intermittent PTH. The purpose of this study was to determine if bisphosphonates and intermittent PTH treatment have impact on human spinal fusion. A systematic review of the literature published between 1980 and 2015 was conducted using major electronic databases. Studies reporting outcomes of human subjects undergoing 1, 2, or 3-level spinal fusion while receiving bisphosphonates and/or intermittent PTH treatment were included. The results of relevant human studies were analyzed for consensus on the effects of these medications in regards to spinal fusion. There were nine human studies evaluating the impact of these medications on spinal fusion. Improved fusion rates were noted in patients receiving bisphosphonates compared to control groups, and greater fusion rates in patients receiving PTH compared to control groups. Prior studies involving animal models found an improved fusion rate and fusion mass microstructure with the use of intermittent PTH. No significant complications were demonstrated in any study included in the analysis. Bisphosphonate use in humans may not be a deterrent to spinal fusion. Intermittent parathyroid use has shown early promise to increase fusion mass in both animal and human studies but further studies are needed to support routine use.
\end{abstract}

Keywords: Lumbar vertebrae; Spinal fusion; Diphosphonates; Bisphosphonates; Parathyroid hormone

\section{Introduction}

As the average age of the population increases, and subsequently the diagnosis of osteoporosis within the aging population, there has been a conscious effort to address this health condition. Osteoporosis is one of the most common metabolic bone diseases in the United States [1]. As bisphosphonate and intermittent parathyroid

\footnotetext{
Received Oct 30, 2016; Accepted Dec 10, 2016

Corresponding author: Michael A. Stone

Department of Orthopaedic Surgery, Keck School of Medicine of USC,

1520 San Pablo, HCT Suite 2000, Los Angeles, CA 90033, USA

Tel: +1-323-226-7204, Fax: +1-323-226-8205, E-mail: Michaelstone55@gmail.com
} 
hormone (PTH) therapy become more widely prescribed to treat osteoporosis, it is important to understand their effect on other physiologic processes. Bisphosphonates inhibit osteoclastic bone resorption and have a direct anabolic effect on bone formation. Non-nitrogen containing bisphosphonates are metabolized into a nonfunctional adenosine triphosphate (ATP) analog which induces osteoclast apoptosis. Nitrogen-containing bisphosphonates can be up to 1,000 times more potent in their action due to their nitrogen side-groups. This class of bisphosphonates inhibits protein prenylation in the mevalonate pathway and blocks farnesyl pyrophosphate synthase resulting in inhibition of the ruffled border formation. PTH exerts its effects via activation of cell surface receptors on bone and renal G-proteins [2]. With continuous administration, PTH favors bone reabsorption; however, with pulsed administration, it favors bone formation [3]. PTH has been shown to increase cortical thickness without increasing porosity in osteoporotic patients. The commercially available form of PTH (Teriparatide) has been shown to decrease vertebral fracture risk in postmenopausal women with osteoporosis [3].

Of particular interest is the impact of bisphosphonates and PTH treatment on spinal fusion. Early studies on animal models have attempted to measure time to fusion and bone fusion mass outcomes. Recent studies have begun to investigate the clinical effect of these medications on spinal fusion, but their impact remains poorly understood. A related study in distraction osteogenesis employed bolus dosing of nitrogen-containing bisphosphonates and showed significant increases in callus volume, mineral content, and strength in treated animals, even in the presence of stress shielding [4]. Additionally, complications after lumbar interbody surgery, such as subsequent vertebral compression fractures, cage subsidence, and loosening of pedicle screws are most frequent in osteoporosis patients [5]. Osteoporosis treatment with these medications may be of benefit to mitigate these complications.

The purpose of our study was to provide a comprehensive review of the current literature regarding bisphospho- nate use and PTH therapy in osteoporotic patients undergoing spinal fusion.

\section{Materials and Methods}

\section{Search strategy}

A comprehensive search of the literature was performed for articles published between 1980 and October 2015 evaluating the effects of bisphosphonates or PTH on spinal fusion. The PubMed (MEDLINE) and BIOSIS databases were queried using the multiple search terms (spinal fusion, pseudarthrosis, bisphosphonates, clodronate, ibandronate, etidronate, alendronate, risedronate, zoledronate, pamidronate, Forteo, teriparatide or PTH) (Table 1). Two independent reviewers screened the titles and abstracts of all the articles for appropriate inclusion.

\section{Study selection process}

Records were retrieved from the electronic search results and exported to EndNote X7 (Thomson Reuters, New York, NY, USA) and all duplicates were removed. Two authors (A.J.K. and M.A.S.) independently reviewed and selected the relevant studies. The eligibility criteria was applied to the selected studies in which case the full text was available for review. Any disagreements were resolved by consensus. In the case where a consensus could not be reached the discrepancy was resolved by a third author (NP).

Exclusion criteria were: (1) studies that did not evaluate spinal fusion (quality, biomechanics, histology), (2) studies lacking control subjects, (3) studies that did not perform statistical analysis or (4) case reports. The search strategy revealed 59 studies from the literature, further screening of the titles and abstracts of these articles identified 30 papers for review. Twenty-one studies were excluded as they pertained to non-human studies, and 3 of which were review papers. This left 9 articles for inclusion of our final review (Fig. 1) [6].

Relevant data were identified and extracted from the

Table 1. Search terms

((“humans"[MeSH Terms] OR "humans"[All Fields] OR “human"[All Fields]) AND (“lumbosacral region"[MeSH Terms] OR (“lumbosacral"[All Fields] AND "region"[All Fields]) OR "lumbosacral region"[All Fields] OR "lumbar"[All Fields]) AND ("Nucl Eng Des/Fusion"[Journal] OR "fusion"[All Fields] OR "FUSION"[Journal] OR "fusion"[All Fields])) AND (("diphosphonates"[MeSH Terms] OR "diphosphonates"[All Fields] OR "bisphosphonates"[All Fields]) OR ("parathyroid hormone"[MeSH Terms] OR ("parathyroid"[All Fields] AND “hormone"[All Fields]) OR "parathyroid hormone"[All Fields])) 


\section{PRISMA 2009 flow diagram}

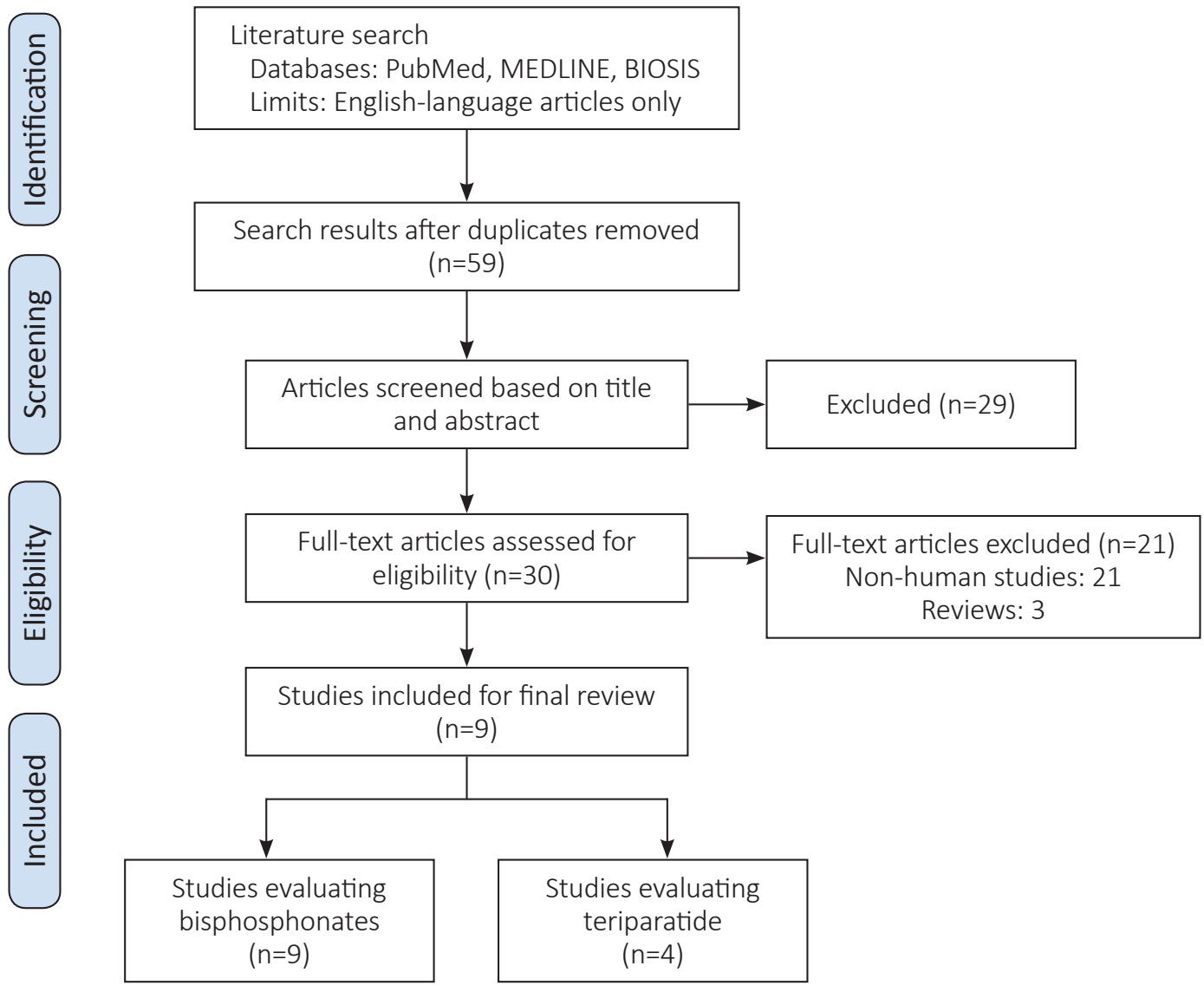

Fig. 1. PRISMA flow diagram for study inclusion (Data from Moher et al., PLoS Med 2009:6:e1000097 [6], on the basis of Open Access).

full text of each study including demographic data, assessment of fusion quality or mass, methodology of fusion assessment and statistical significance, if available. Some of the studies stratified data by treatment groups, and in these cases, the extracted data were appropriately stratified to reflect this. The heterogeneity of the methodology used in the included studies precluded meta-analysis.

\section{Level of evidence}

Level of evidence of each study was independently graded by two of the authors using the criteria outlined by Wright et al. [7]. Any disagreements in the grading of level of evidence was resolved by a third reviewer.

\section{Results}

Initially, 59 human and animal studies pertaining to adjuvant bisphosphonate and/or PTH for improvement of spinal fusion were retrieved from PubMed and Biosis. After review, 50 studies were excluded as they did not portend to human studies in addition to the criteria listed in Fig. 1 [6]. Nine studies that matched both the inclusion and exclusion criteria were included in our final analysis. Four studies were graded as Level III, four studies were graded as Level II, and one study was graded as Level I. All studies evaluated patients with osteoporosis confirmed with dual-energy X-ray absorptiometry (DEXA) with spinal stenosis, degenerative spondylolisthesis, and/ or foraminal stenosis. All patients underwent one, two or three level posterior lumbar fusion with instrumentation. All studies mentioned that they used local autograft for their graft materials, with Park et al. supplementing it with the use of iliac crest autograft and/or allograft bone and Nagahama et al. supplementing local autograft with Betatricalcium phosphate. There was no mention of the use 
of bone morphogenic protein or other osteoconductive materials.

Zoledronic acid was used in three studies, Risedronate in three studies, and Alendronate in three studies. Teriparatide was used in four studies. Zoledronic acid was given as a $5 \mathrm{mg}$ dose three days prior to surgery in one study [8], two weeks after surgery as single dose in another study [9], and three days postoperatively and yearly thereafter in the final study [10]. Risedronate dose was $2.5 \mathrm{mg}$ oral daily two months before and continued ten months after surgery in one study [11], $17.5 \mathrm{mg}$ and given weekly starting two months before surgery and continued for eight months after surgery in another study [12], and started three months before surgery in the final study [13], however they did not track which patients received Risedronate versus Teriparatide postoperatively. Alendronate was administered as $35 \mathrm{mg}$ weekly prior to surgery and continued until follow-up at one year in one study [14] and $91 \mathrm{mg}$ weekly for at least one year in another study [15]. Teriparatide was given as a daily $20 \mu \mathrm{g}$ subcutaneous dose in all studies. Dosing was given starting two months before surgery and continued for ten months after surgery [11], in 3-month cycles [15], beginning two months before surgery and continued for eight months after surgery [12], and the final study was given in short duration (less than six months) or long duration (greater than six months) groups [13]. Demographic information is listed in Table 2 [8-16].

\section{Effect of bisphosphonates on spinal fusion}

Nagahama et al. measured intervertebral fusion radiographically with computed tomography (CT) scan at three, six, nine, and twelve months after single level posterior lumbar interbody fusion. Patients were randomly assigned to begin alendronate $(\mathrm{n}=19,35 \mathrm{mg} / \mathrm{wk})$ or vitamin $\mathrm{D}(\mathrm{n}=17,1 \mu \mathrm{g} /$ day $)$ within one week after surgery and surgeons were blinded to the treatment protocol. Fusion was defined as less than 5 degrees of angular motion on flexion and extension radiographs at the fusion level and bridging cortical bone. Cage subsidence was measured and defined as greater than $2 \mathrm{~mm}$ of vertical migration from baseline. At one year postoperatively, fusion was observed in 95\% (18/19) of the alendronate group and 65\% $(11 / 17)$ of the control group $(p=0.025)$. There were also higher rates of cage subsidence in the control group (5 patients) versus the alendronate group (1 patient), however this was not statistically significant (Table 3) [8-16].

Bone alkaline phosphatase was elevated by $52 \%$ at 1 month postoperatively, but decreased to below baseline by

Table 2. Demographic information

\begin{tabular}{|c|c|c|c|c|c|c|}
\hline Study & Design & $\begin{array}{l}\text { Level of } \\
\text { evidence }\end{array}$ & No. & Drug & Dose & Duration \\
\hline Li et al. [8] & Prospective & I & 82 & Zoledronic acid & $5 \mathrm{mg}$ & $\begin{array}{l}1 \text { Time infusion } 3 \text { days after } \\
\text { surgery }\end{array}$ \\
\hline $\begin{array}{l}\text { Nagahama et al. } \\
\text { [14] }\end{array}$ & Prospective & $\|$ & 36 & $\begin{array}{l}\text { Alendronate or } \\
\text { alfacalcidol }\end{array}$ & $35 \mathrm{mg} / \mathrm{wk}$ & $\begin{array}{l}\text { Started } 1 \text { week after surgery } \\
\text { and continued for } 12 \text { months }\end{array}$ \\
\hline Park et al. [9] & Retrospective & III & 44 & Zoledronic acid & $5 \mathrm{mg}$ & Single dose \\
\hline Tu et al. [10] & Retrospective & III & 64 & Zoledronic acid & $5 \mathrm{mg}$ & $\begin{array}{l}3 \text { Days postoperative, then } \\
\text { yearly }\end{array}$ \\
\hline Kim et al. [16] & Retrospective & III & 44 & Alendronate & $35 \mathrm{mg} / \mathrm{wk}$ & Not recorded \\
\hline Ohtori et al. [11] & Prospective & $\|$ & 62 & $\begin{array}{l}\text { Teriparatide } \\
\text { risedronate }\end{array}$ & $\begin{array}{l}\text { Daily subcutaneous } \\
\text { injection } 20 \mu \mathrm{g} \text { daily } \\
2.5 \mathrm{mg}\end{array}$ & $\begin{array}{l}\text { Administered for } 2 \text { months } \\
\text { before and } 10 \text { months after } \\
\text { surgery }\end{array}$ \\
\hline Ohtori et al. [12] & Prospective & $\|$ & 57 & $\begin{array}{l}\text { Teriparatide } \\
\text { risedronate }\end{array}$ & $\begin{array}{l}\text { Daily subcutaneous } \\
\text { injection } 20 \mu \mathrm{g} \\
17.5 \mathrm{mg} \text { weekly }\end{array}$ & $\begin{array}{l}\text { Both started } 2 \text { months } \\
\text { before surgery and continued } \\
8 \text { months after surgery }\end{array}$ \\
\hline Ohtori et al. [13] & Retrospective & III & 45 & $\begin{array}{l}\text { Teriparatide } \\
\text { risedronate }\end{array}$ & $\begin{array}{l}\text { Daily } 20 \mu \mathrm{g} 17.5 \text { mg } \\
\text { weekly }\end{array}$ & $<6$ months, $>6$ months \\
\hline Cho et al. [15] & Prospective & $\|$ & 47 & $\begin{array}{l}\text { Teriparatide } \\
\text { alendronate }\end{array}$ & $\begin{array}{l}\text { Daily subcutaneous } \\
\text { injection } 20 \mu \mathrm{g} 91.37 \\
\text { mg weekly }\end{array}$ & $\begin{array}{l}\text { Started and continued for } \\
12 \text { months after surgery }\end{array}$ \\
\hline
\end{tabular}


Table 3. Assessment of fusion

\begin{tabular}{|c|c|c|c|c|}
\hline Study & Medication & Treatment & Fusion rate & Fusion mass \\
\hline Li et al. [8] & Zoledronic acid & 1, 2, or 3 Level TLIF & - & Not recorded \\
\hline $\begin{array}{l}\text { Nagahama et al. } \\
\text { [14] }\end{array}$ & $\begin{array}{l}\text { Alendronate or } \\
\text { alfacalcidol }\end{array}$ & 1 Level PLIF & $\begin{array}{l}18 / 19(95 \%) \text { In the alendronate group } \\
11 / 17(65 \%) \text { Control group }\end{array}$ & Not recorded \\
\hline Park et al. [9] & $\begin{array}{l}\text { Zoledronic } \\
\text { acid }\end{array}$ & 1 or 2 Level PLIF & $\begin{array}{l}\text { Group 1: bilateral posterolateral lumbar } \\
\text { fusion with autogenous iliac and local bone } \\
\text { grafting \& zoledronic acid - } 100 \%(11 / 11) \\
\text { Group 2: allograft and autograft bone \& } \\
\text { zoledronic acid - 100\% (11/11) } \\
\text { Group 3: autogenous iliac and local bone } \\
\text { grafting - 100\% (11/11) } \\
\text { Group 4: allograft and autograft bone - } \\
82 \%(9 / 11)\end{array}$ & $\begin{array}{l}\text { Measured at } 6 \text { months } \\
\text { Group 1: } 8,814 \mathrm{~mm}^{3} \\
\text { Group 2: } 8,035 \mathrm{~mm}^{3} \\
\text { Group 3: } 8,383 \mathrm{~mm}^{3} \\
\text { Group 4: } 7,550 \mathrm{~mm}^{3}\end{array}$ \\
\hline Tu et al. [10] & $\begin{array}{l}\text { Zoledronic } \\
\text { acid }\end{array}$ & 1 or 2 Level LIF & $\begin{array}{l}75 \% \text { In the zoledronic acid group } \\
56 \% \text { In the control group }\end{array}$ & Not recorded \\
\hline Kim et al. [16] & Alendronate & 1 Level PLIF & $\begin{array}{l}66.7 \% \text { In the alendronate group } \\
73.9 \% \text { In the control group }\end{array}$ & Not recorded \\
\hline Ohtori et al. [11] & $\begin{array}{l}\text { Teriparatide } \\
\text { risedronate }\end{array}$ & $\begin{array}{l}1 \text { or } 2 \text { Level PLF, } \\
\text { Bilateral facet fusions }\end{array}$ & Not assessed & Not recorded \\
\hline Ohtori et al. [12] & $\begin{array}{l}\text { Teriparatide } \\
\text { risedronate }\end{array}$ & $\begin{array}{l}1 \text { or } 2 \text { Level PLF, } \\
\text { Bilateral facet fusions }\end{array}$ & $\begin{array}{l}82 \% \text { In teriparatide group, } \\
68 \% \text { In risedronate group }\end{array}$ & Not recorded \\
\hline Ohtori et al. [13] & $\begin{array}{l}\text { Teriparatide } \\
\text { risedronate }\end{array}$ & $\begin{array}{l}1 \text { or } 2 \text { Level PLF, } \\
\text { Bilateral facet fusions }\end{array}$ & $\begin{array}{l}70 \% \text { Fusion in the risedronate group } \\
78 \% \text { Fusion in the short-duration teriparatide } \\
\text { treatment group } \\
86 \% \text { Fusion in the long-duration treatment } \\
\text { group }\end{array}$ & Not recorded \\
\hline Cho et al. [15] & $\begin{array}{l}\text { Teriparatide } \\
\text { alendronate }\end{array}$ & 1 or 2 Level PLIF & $\begin{array}{l}\text { 93\% In teriparatide group, } \\
96 \% \text { In alendronate group }\end{array}$ & Not recorded \\
\hline
\end{tabular}

TLIF, transforaminal lumbar interbody fusion; PLIF, posterior lumbar interbody fusion; LIF, lumbar interbody fusion; PLF, posterolateral lumbar fusion.

6 months suggesting that alendronate decreased bone formation after the early phase. Type 1 collagen cross-linked $\mathrm{N}$-telopeptide, a marker of bone resorption, decreased to below baseline in the alendronate group suggesting inhibition of resorption immediately after surgery. The study was graded as Level II as it was underpowered due to small sample size, absence of inter-rater reliability data, use of non-validated fusion measures, and lack of true control arm (placebo or non-medicated) [14].

Li et al. [8] used CT with multi-planar reconstruction at six months postoperatively to evaluate intervertebral fusion after transforaminal lumbar interbody fusion (TLIF) in a randomized, double-blind, placebo-controlled trial of 82 subjects. The zoledronic acid group showed no statistical difference in nonunion rates compared to the control group at six months $(27.9 \%$ versus $33.9 \%, p=0.60)$, and no differences at twelve months (11.5\% versus $14.5 \%$, $p=0.82$ ). There were no statistically significant differences in Oswestry disability index (ODI) scores. Biochemical measurements were also done which included serum calcium, phosphate, amino terminal propeptides of type I collagen (PINP), C-telopeptide of type I collagen (CTX), PTH and 25-hydroxyvitamin D. The zoledronic acid group significantly decreased PINP $(p<0.0001)$ and CTX $(p<0.0001)$ compared to controls in the postoperative period, which reflects decreased bone formation and bone resorption respectively. The results of this study may differ from those of Nagahama et al. [14] because risedronate and alendronate have different pharmacokinetics, and different interbody techniques (TLIF and posterior lumbar interbody fusion [PLIF]) were used. This study was graded as Level I.

Park et al. [9] retrospectively reviewed 4 groups of patients who underwent 1 or 2-level posterolateral lumbar fusions for degenerative stenosis: group 1, autograft and zoledronic acid; group 2, allograft and zoledronic acid; 
group 3, autograft only; and group 4, allograft only. A blinded assessor interpreted radiographs and three-dimensional CT which were performed up to 6 months after surgery to quantify fusion masses [9]. Groups 1, 2, and 3 achieved a 100\% fusion rate and Group 4 exhibited a fusion rate of $82 \%$; however, there were no significant differences between groups $(p>0.05)$. Similarly, fusion mass volumes were not different between groups ( $p>0.05)$. All groups showed significant improvement in visual ananalog scale (VAS), ODI and SF-36 scores, however there were no significant differences between groups in any of these clinical outcomes [9]. This study was graded as level III because it was underpowered, retrospective design, small sample sizes, and short-term follow-up.

Tu et al. [10] performed a retrospective review comparing zoledronic acid and a control group undergoing one or two-level lumbar interbody fusion. Fusion was assessed with radiographic evaluation and analysis of pedicle screw loosening, vertebral compression fractures, subsidence, and lucencies between vertebral bodies which indicated nonunion. Patients were followed for two years. The final fusion rate was higher in the zoledronic acid group compared to control group (75\% versus 56\%), however there is no mention if these numbers were able to reach statistical significance. Vertebral compression fractures, pedicle screw loosening, and cage subsidence were all significantly lower in the zoledronic acid group compared to control group (19\% versus 51\%), (18\% versus $45 \%)$, (28\% versus $54 \%$ ), respectively. There were no differences in VAS and ODI scores up to 9 months postoperatively, however both scores were significantly lower in the zoledronic acid group at 2 years [10]. This study was graded level III and is limited by its retrospective design, inability to determine if similar interbody techniques were used among all patients, failure to perform CT imaging on all patients, use of only one imaging reviewer, and lack of statistical analysis regarding fusion rates between groups.

Kim et al. [16] performed a retrospective analysis of 44 patients with osteoporosis undergoing single level PLIF comparing alendronate to control group. Radiographs were evaluated for evidence of spinal fusion and flexion extension views. Modic endplate changes were recorded. They showed a $66.7 \%$ fusion rate in the alendronate group and $73.9 \%$ fusion rate in the control group which was not significantly different. The authors did not record duration of bisphosphonate treatment [16].

\section{Effect of PTH on spinal fusion}

Ohtori et al. [12] reported their results of a prospective study of postmenopausal women with osteoporosis who underwent one- or two-level instrumented lumbar posterolateral fusion with local bone graft for degenerative spondylolisthesis. Fifty-seven women were divided into a teriparatide groups $(\mathrm{n}=29,20 \mu \mathrm{g}$ subcutaneous [SC] daily) or a bisphosphonate group ( $\mathrm{n}=28,17.5 \mathrm{mg}$ of oral risedronate weekly). At 1-year after surgery, the authors found that the rate of bone union as evaluated by CT was $82 \%$ in the teriparatide group and $68 \%$ in the risedronate group ( $p=0.02$ ). The rate of bone fusion was also faster in patients who received teriparatide (mean, $8 \pm 2.5$ months) rather than risedronate (mean, $9.7 \pm 2$ months) $(p=0.03)$. Instability as determined by radiography (greater than $1.5^{\circ}$ of movement between flexion and extension) was more common in the risedronate group (26\% versus $16 \%$ of instrumented segments, $p=0.02$ ), but measurements may have been obscured by instrumentation and implants rather than union, as the implants may have provided immediate stability. There were no differences in VAS or ODI scores at follow-up between the two groups. This study was graded as Level III because of small sample size and presence of comparison group, but lack of a nonmedicated control group.

In 2013, Ohtori et al. [11] prospectively studied pedicle screw loosening after lumbar fusion surgery in 62 postmenopausal women with osteoporosis who were treated with teriparatide ( $\mathrm{n}=20,20 \mu \mathrm{g}$ SC daily), a bisphosphonate $(n=20,2.5 \mathrm{mg}$ of oral risedronate daily), or without medications $(n=22)$. All patients underwent 1- or 2-level instrumented posterolateral fusions with local bone graft for spondylolisthesis and continued the treatment medication for 10 months. Pedicle screw loosening was determined by lucent zones around screws on radiographs and CT imaging for up to 1-year after surgery. Readings were performed by three observers and screws were considered loose if two observers identified lucent zones. At 1-year follow-up, the teriparatide group had significantly less pedicle screw loosening ( $7 \%$ on radiographs and $13 \%$ on CT) compared to the bisphosphonate ( $13 \%$ and $26 \%$, respectively) and non-medicated groups (15\% and $25 \%$, respectively). There were no differences in screw loosening between the bisphosphonate and control group ( $p>0.05)$, and VAS and ODI scores were not different between the 3 groups regardless of screw loosening. Diabetes, use of 
anti-inflammatory medication, smoking status, and bone mineral density could not account for rates of screw loosening between groups ( $p>0.05)$. This study was graded as Level III because surgeons were not blinded to the treatment arm, sample sizes were limited, radiographic measure of screw loosening (lucency $\geq 1 \mathrm{~mm}$ at bone-screw interface) has not been validated, and it is unclear if interrater reliability was established.

A subsequent retrospective investigation by Ohtori et al. [13] investigated the most effective duration of teriparatide for osteoporotic women undergoing lumbar posterolateral fusion. All patients had a diagnosis of lumbar stenosis with degenerative spondylolisthesis and underwent 1- or 2-level instrumented fusion with local bone graft and bilateral facet fusions. Forty-five women were divided into 3 groups: short-term teriparatide (mean duration, 5.5 months; $20 \mu \mathrm{g} \mathrm{SC}$ daily), long-term teriparatide (mean duration, 13 months; $20 \mu \mathrm{g}$ SC daily), and a bisphosphonate group (mean duration, 13 months; $17.5 \mathrm{mg}$ of oral risedronate weekly). All patients received teriparatide or risedronate for 3 months prior to surgery. At 1-year, union across the transverse processes on CT imaging for the risedronate, short-term, and long-term teriparatide groups was $70 \%, 78 \%$, and $86 \%$, respectively. Fusion in the teriparatide groups was greater than the bisphosphonate group $(p<0.05)$, and prevalence of union was greater in the longterm versus short-term group ( $p=0.045)$. This study was graded Level III because of its small sample size, presence of comparison but lack of control group, and absence of standardized outcomes measures. Selection bias in whom to enroll is another limitation of this retrospective study. The authors also state that patients received bisphosphonates after treatment with teriparatide "for ethical reasons".

Cho et al. [15] prospectively compared teriparatide and bisphosphonate therapy in 47 osteoporotic women who underwent PLIF with pedicle screw fixation for lumbar stenosis with instability. The teriparatide group $(n=23)$ received a $20 \mu \mathrm{g}$ daily subcutaneous dose for 3 -month cycles alternating with 3-week intervals of oral alendronate $91 \mathrm{mg}$ weekly and the bisphosphonate group $(\mathrm{n}=24)$ received oral alendronate $91 \mathrm{mg}$ weekly. Treatment medications were prescribed for 1 year after surgery. At 24 months after surgery, there were no differences in interbody fusion rate, pedicle screw loosening, cage subsidence, bone mineral density scores, or clinical outcome scores between groups. The study was graded as Level II because of nonrandom allocation to treatment groups and small sample size. Additional limitations are the cyclic teriparatide regimen, use of one imaging reviewer, lack of intra-rater reliability reporting, and utilization of a nonvalidated fusion classification.

\section{Discussion}

Anti-osteoporotic medications are being used more frequently as adjunctive treatments for fusion in osteoporotic patients undergoing instrumented lumbar surgery. It has been estimated that at least $72 \%$ of Caucasian women over the age of 65 years and $93 \%$ over 75 years of age are candidates for anti-osteoporotic medications [17]. In contrast, approximately $34 \%$ and $50 \%$ of Caucasian men over the ages of 65 and 75 years, respectively, are likely to be recommended for drug treatment [17]. The purpose of our study was to perform a systematic review of the effects of bisphosphonates and intermittent PTH on spinal fusion. At the time of our review, 9 studies of human subjects were available (4 retrospective and 5 prospective), two of which were randomized controlled trials.

Bisphosphonates have been utilized in spinal fusion procedures because of their efficacy in fracture reduction in osteoporotic patients. Among all anti-resorptive medications, bisphosphonates are the only medications that are proven to reduce the rate of hip fractures in large, randomized controlled trials [18-20]. However, the effect of bisphosphonates on spinal fusion are less wellestablished and results have been controversial [21,22]. Animal studies have shown increased size and density of fusion masses but decreased fusion rates [21], increased bone mineral content with improved fusion rates [22], improved bone-screw interface fixation after pedicle screw placement [23], and dose-dependent effects on graft incorporation [24-26]. Many of the previous studies involving animal studies which evaluated the effects of alendronate administered for several weeks before and after spinal fusion showed a negative effect on fusion rate [15,17]. Similarly, pamidronic acid administered for 4 weeks preoperatively and then daily for 4 weeks postoperatively was also shown to have negative effects on spinal fusion in a rabbit model [27].

Bisphosphonate studies involving human subjects have not conclusively supported an improvement in fusion after lumbar surgery. All 8 studies included a bisphosphonate treatment group; however, 3 lacked a non-medicated control group, 3 studies were comparisons against teriparatide, 
1 evaluated screw loosening but failed to mention fusion rates, and 1 included a vitamin D control group. Only one study found that a bisphosphonate was superior to vitamin D via statistical analysis [14]; another study reported an approximately $20 \%$ greater fusion rate with zoledronic acid compared to controls but failed to report statistical significance [10]. Pain and functional outcomes after bisphosphonate treatment were not improved greater than that of controls in any study, but a reduction in secondary outcomes such as compression fractures and hip fractures has been found in several studies. Additionally, studies have shown that bisphosphonates may be used to increase bone-screw fixation in osteoporotic long bones [21] as well as improve bone-screw interface fixation in an experimental spine models [23]. Biochemical markers support an alteration in bone formation and resorption which results in a larger and denser fusion mass; unfortunately, the ability to form a solid fusion is not improved.

Intermittent recombinant PTH appears to have a similar outcome record when comparing animal model studies to that of humans. Preclinical data has supported the use of intermittent PTH for lumbar spinal fusion. In three animal posterolateral fusion studies, the use of PTH had a positive effect on achieving faster fusion rates than that of the use of autograft only. In human studies, teriparatide treatment groups had earlier time to union compared to placebo for osteoporotic $[24,28]$ patients with distal radii and pelvic fractures [29]. Promising results of teriparatide on bony healing have similarly been reported in spine patients. Rubery and Bukata [30] confirmed healing with CT scans and resolution of neck pain after delayed union of three type III odontoid fractures in osteoporotic females. However, the study is limited by a small sample size, retrospective design, and variable durations of teriparatide treatment. Larger studies have also shown promising results for achieving solid fusion and reducing pedicle screw loosening, suggesting an improvement of bone quality in the marrow and pedicles [11-13]. Despite strong histological evidence of improved fusion after PTH no differences in clinical outcomes have been established between PTH, bisphosphonates, and controls [11,12].

One study failed to find a difference between PTH and alendronate therapy [15]. A unique feature of the experimental group is the cyclical 3-month PTH regimen alternating with 3 months of alendronate. The comparison group was administered alendronate for at least 1 year. Cyclic PTH results in the early phase (bone formation) of
PTH action [31] and thereby limits the bone remodeling phase. As the authors stated, the 3-month delay between PTH treatments may have been too short to observe an improvement in bone formation, given that bisphosphonates have an opposing effect on bone turnover compared to PTH. Additionally, the authors were only able to assess the efficacy of the first cycle of PTH followed by alendronate and were unable to draw conclusions regarding subsequent cycles. Studies of longer PTH cycles are needed to draw firm conclusions.

Comparative studies between PTH and bisphosphonates have found treatment with PTH to be superior in regards to bone formation and fusion [11-13] with the exception of one study which found no difference [15]. Animal studies have similarly concluded that PTH produces more mature bone formation and larger fusion masses [28]. However, maximum follow-up among these studies was 24 months $[13,15]$ and long-term clinical data is unavailable. Insufficient long-term clinical outcome data prohibits making strong conclusions between fusion and outcomes in patients who received anti-resorptive or bone-producing medications. However, successful spinal fusion has been correlated with improved patient outcomes in long-term studies in patients who have not received these medications [32].

New data in fracture healing in rat models using antisclerostin antibody has shown some promising results when used in conjunction with an osteoinductive agent such as bone morphogenetic protein-2 (BMP-2). In a rat fracture model, Tinsley et al. [27] showed that antisclerostin antibody with BMP-2 had stronger biomechanical properties than non-fractured femurs. Although this is study regarding fracture repair in an animal model, this agent has shown promise in bone healing, and may be on the horizon for use in spinal fusion alongside PTH and bisphosphonates for patients with osteoporosis undergoing posterior spine fusion.

The present study has several limitations. The analysis was limited by the integrity and sample sizes of the studies which were reviewed. Ideally, all studies included in this review would be limited to large-scale randomized controlled trials on humans, however this was not possible based on the available literature. As discussed earlier, there is heterogeneity in treatment type, medication dosing, timing, and duration, as well as measurement of outcomes. Selection bias was also a concern in the retrospective studies included in this review. 


\section{Conclusions}

Bisphosphonates have shown promise in both animal and human studies to be safe and effective in osteoporotic patients undergoing lumbar spinal fusion. Although the evidence in the literature is heterogeneous, some conclusions regarding its efficacy may be drawn. PTH has also been shown to increase bone mass and rates of fusion compared to controls. This data, however should be used cautiously based on the nonuniformity and low sample sizes of the studies provided. Larger prospective randomizedcontrolled trials are needed before firm conclusions can be made regarding changes in current clinical treatment strategies for this patient population.

\section{Conflict of Interest}

No potential conflict of interest relevant to this article was reported.

\section{ORCID}

Michael A. Stone: 0000-0002-9024-9584

Andre M. Jakoi: 0000-0002-8660-6833

Justin A. Iorio: 0000-0003-2689-7533

Martin H. Pham: 0000-0003-4468-6318

Neil N. Patel: 0000-0002-6972-7238

Patrick C. Hsieh: 0000-0002-7206-4842

John C. Liu: 0000-0002-6085-0926

Frank L. Acosta: 0000-0002-8352-199X

Raymond Hah: 0000-0001-7513-3519

Jeffrey C. Wang: 0000-0001-5224-454X

\section{References}

1. US Department of Health and Human Services, Office of the Surgeon General. Bone health and osteoporosis: a report of the Surgeon General. Rockville, MD: U.S. Dept. of Health and Human Services, Public Health Service, Office of the Surgeon General; 2004.

2. Rosen CJ, Bilezikian JP. Clinical review 123: anabolic therapy for osteoporosis. J Clin Endocrinol Metab 2001;86:957-64.

3. Armbrecht HJ, Wongsurawat N, Zenser TV, Davis $\mathrm{BB}$. Effect of PTH and 1,25(OH)2D3 on renal 25(OH)D3 metabolism, adenylate cyclase, and pro- tein kinase. Am J Physiol 1984;246:E102-7.

4. Little DG, Smith NC, Williams PR, et al. Zoledronic acid prevents osteopenia and increases bone strength in a rabbit model of distraction osteogenesis. J Bone Miner Res 2003;18:1300-7.

5. Halvorson TL, Kelley LA, Thomas KA, Whitecloud TS 3rd, Cook SD. Effects of bone mineral density on pedicle screw fixation. Spine (Phila Pa 1976) 1994;19:2415-20.

6. Moher D, Liberati A, Tetzlaff J, Altman DG, The PG. Preferred reporting items for systematic reviews and meta-analyses: the PRISMA statement. PLoS Med 2009;6:e1000097.

7. Wright JG, Swiontkowski MF, Heckman JD. Introducing levels of evidence to the journal. J Bone Joint Surg Am 2003;85:1-3.

8. Li C, Wang HR, Li XL, Zhou XG, Dong J. The relation between zoledronic acid infusion and interbody fusion in patients undergoing transforaminal lumbar interbody fusion surgery. Acta Neurochir (Wien) 2012;154:731-8.

9. Park YS, Kim HS, Baek SW, Kong DY, Ryu JA. The effect of zoledronic acid on the volume of the fusionmass in lumbar spinal fusion. Clin Orthop Surg 2013;5:292-7.

10. Tu CW, Huang KF, Hsu HT, Li HY, Yang SS, Chen YC. Zoledronic acid infusion for lumbar interbody fusion in osteoporosis. J Surg Res 2014;192:112-6.

11. Ohtori S, Inoue G, Orita S, et al. Comparison of teriparatide and bisphosphonate treatment to reduce pedicle screw loosening after lumbar spinal fusion surgery in postmenopausal women with osteoporosis from a bone quality perspective. Spine (Phila $\mathrm{Pa}$ 1976) 2013;38:E487-92.

12. Ohtori S, Inoue G, Orita S, et al. Teriparatide accelerates lumbar posterolateral fusion in women with postmenopausal osteoporosis: prospective study. Spine (Phila Pa 1976) 2012;37:E1464-8.

13. Ohtori S, Orita S, Yamauchi K, et al. More than 6 months of teriparatide treatment was more effective for bone union than shorter treatment following lumbar posterolateral fusion surgery. Asian Spine J 2015;9:573-80.

14. Nagahama K, Kanayama M, Togawa D, Hashimoto T, Minami A. Does alendronate disturb the healing process of posterior lumbar interbody fusion? A prospective randomized trial. J Neurosurg Spine 
2011;14:500-7.

15. Cho PG, Ji GY, Shin DA, Ha Y, Yoon DH, Kim KN. An effect comparison of teriparatide and bisphosphonate on posterior lumbar interbody fusion in patients with osteoporosis: a prospective cohort study and preliminary data. Eur Spine J 2017;26:691-7.

16. Kim SM, Rhee W, Ha S, Lim JH, Jang IT. Influence of alendronate and endplate degeneration to single level posterior lumbar spinal interbody fusion. Korean J Spine 2014;11:221-6.

17. Donaldson MG, Cawthon PM, Lui LY, et al. Estimates of the proportion of older white women who would be recommended for pharmacologic treatment by the new U.S. National Osteoporosis Foundation Guidelines. J Bone Miner Res 2009;24:675-80.

18. Cummings SR, Black DM, Thompson DE, et al. Effect of alendronate on risk of fracture in women with low bone density but without vertebral fractures: results from the Fracture Intervention Trial. JAMA 1998;280:2077-82.

19. Harris ST, Watts NB, Genant HK, et al. Effects of risedronate treatment on vertebral and nonvertebral fractures in women with postmenopausal osteoporosis: a randomized controlled trial: Vertebral Efficacy With Risedronate Therapy (VERT) Study Group. JAMA 1999;282:1344-52.

20. McClung MR, Geusens P, Miller PD, et al. Effect of risedronate on the risk of hip fracture in elderly women: Hip Intervention Program Study Group. N Engl J Med 2001;344:333-40.

21. Huang RC, Khan SN, Sandhu HS, et al. Alendronate inhibits spine fusion in a rat model. Spine (Phila Pa 1976) 2005;30:2516-22.

22. Bransford R, Goergens E, Briody J, Amanat N, Cree A, Little D. Effect of zoledronic acid in an L6-L7 rabbit spine fusion model. Eur Spine J 2007;16:557-62.

23. Xue Q, Li H, Zou X, et al. Alendronate treatment improves bone-pedicle screw interface fixation in posterior lateral spine fusion: an experimental study in a porcine model. Int Orthop 2010;34:447-51.
24. Lehman RA Jr, Kuklo TR, Freedman BA, Cowart JR, Mense MG, Riew KD. The effect of alendronate sodium on spinal fusion: a rabbit model. Spine J 2004;4:36-43.

25. Babat LB, McLain R, Milks R, Ferrara L, Sohn MJ. The effects of the antiresorptive agents calcitonin and pamidronate on spine fusion in a rabbit model. Spine J 2005;5:542-7.

26. Takahata $M$, Ito $M$, Abe $Y$, Abumi K, Minami A. The effect of anti-resorptive therapies on bone graft healing in an ovariectomized rat spinal arthrodesis model. Bone 2008;43:1057-66.

27. Tinsley BA, Dukas A, Pensak MJ, et al. Systemic administration of sclerostin antibody enhances bone morphogenetic protein-induced femoral defect repair in a rat model. J Bone Joint Surg Am 2015;97:1852-9.

28. O'Loughlin PF, Cunningham ME, Bukata SV, et al. Parathyroid hormone (1-34) augments spinal fusion, fusion mass volume, and fusion mass quality in a rabbit spinal fusion model. Spine (Phila Pa 1976) 2009;34:121-30.

29. Aspenberg P, Genant HK, Johansson T, et al. Teriparatide for acceleration of fracture repair in humans: a prospective, randomized, double-blind study of 102 postmenopausal women with distal radial fractures. J Bone Miner Res 2010;25:404-14.

30. Rubery PT, Bukata SV. Teriparatide may accelerate healing in delayed unions of type III odontoid fractures: a report of 3 cases. J Spinal Disord Tech 2010;23:151-5.

31. Cosman F, Nieves J, Zion M, Woelfert L, Luckey M, Lindsay R. Daily and cyclic parathyroid hormone in women receiving alendronate. $\mathrm{N}$ Engl J Med 2005;353:566-75.

32. Kornblum MB, Fischgrund JS, Herkowitz HN, Abraham DA, Berkower DL, Ditkoff JS. Degenerative lumbar spondylolisthesis with spinal stenosis: a prospective long-term study comparing fusion and pseudarthrosis. Spine (Phila Pa 1976) 2004;29:72633. 